\title{
Revisão da compartimentação geomorfológica da Plataforma Continental Norte do Rio Grande do Norte, Brasil
}

\author{
Moab Praxedes Gomes ${ }^{1}$ \& Helenice Vital ${ }^{2}$
}

\begin{abstract}
Resumo Diversos estudos de superfície e subsuperfície têm sido realizados sobre a Plataforma Continental Norte do Rio Grande do Norte com o objetivo de se obter sua caracterização física dos sedimentos do intervalo cronoestratigráfico do Cenozóico. O presente estudo sintetiza os resultados obtidos no âmbito geológico e geomorfológico desses trabalhos, complementando-os com novos dados de batimetria e sensoriamento remoto. Esses dados associados aos dados preexistentes de sedimentologia permitiram a delimitação de três ambientes distintos sobre a plataforma e a caracterização das principais feições desses ambientes. $\mathrm{O}$ primeiro ambiente foi caracterizado como plataforma interna, a qual apresenta predominância de sedimentos siliciclásticos envolvendo extensos campos de dunas longitudinais sendo limitada pela isóbata de $15 \mathrm{~m}$. O segundo ambiente é a plataforma média a qual caracteriza-se pela ocorrência mista de sedimentos siliciclásticos e bioclásticos e dunas transversais entre as isóbatas de 15 e $25 \mathrm{~m}$. O terceiro ambiente é a plataforma externa, com sedimentos bioclásticos e proeminentes desníveis batimétricos, sendo mais estreita e com declividade superior a da plataforma média. Essa porção, de plataforma externa, limita-se com a plataforma média por uma extensa linha de antigas rochas praiais na isóbata de $25 \mathrm{~m}$ e com o talude continental na isóbata de $40 \mathrm{~m}$. O talude e o sopé continental apresentam um grande desnível até a planície abissal a cerca de $2000 \mathrm{~m}$. Algumas feições como vales incisos e corpos arenosos isolados interceptam esses três ambientes e geralmente estão associados a controles estruturais provavelmente neotectônicos.
\end{abstract}

Palavras-chave: Plataforma continental, geomorfologia, batimetria e sensoriamento remoto.

\begin{abstract}
Partitioning geomorphology review of the North Continental Shelf of Rio Grande do Norte, Brazil. Different works deal with surface and subsurface geomorphology on Modern Continental Shelf of Rio Grande do Norte state. Their objectives were the physical characterization of Cenozoic deposits. This paper resumes the obtained results in those previous geomorphology works and inserts new bathymetric and remote sensing data. These data associated with sedimentological data allow a better delimitation of this continental shelf into three different environments: One environment is the inner shelf. In this place there are siliciclastics sediments and large longitudinal dunes under bathymetric depth of 15 meters. The other environment is the mid shelf. This region has a mix of siliciclastic and carbonate sediments, and transversal dunes between 15 and 25 meters deep. The last environment is the outer shelf. Carbonates sediments are dominants in this area. This part of the shelf is narrow between 25 and 40 meters depth. An old beachrock chain at the 25 $\mathrm{m}$ isobath marks the limit between mid- and outer shelf. The shelf passes seawards into a steep slope; it extend until the basin plain, about 2000 meters. Others bedforms area also present on this shelf, such as shelf canyons, reefs, isolated shallow-marine sand bodies and old beachrocks chains, in general associated with neotectonic.
\end{abstract}

Keywords: Continental shelf, geomorphology, bathymetric and remote sensing.

INTRODUÇÃO O presente trabalho apresenta uma síntese das feições geomorfológicas e a compartimentação da Plataforma Continental norte do Rio Grande do Norte (Fig. 1) em Plataforma Interna, Média e Externa utilizando análise de dados batimétricos e imagens de satélite, associados aos dados sedimentológicos preexistentes (Vital et al. 2008). Essa região compreende a extensão imersa da Bacia Potiguar e é caracterizada como uma plataforma mista composta por uma cobertura de sedimentos siliciclásticos, carbonato-siliciclásticos e carbonáticos (Vital et al. 2005), que abriga diversos compartimentos de relevo como dunas submersas, bancos de recifes de corais e rochas praiais (beachrocks), vales incisos, dentre outros que configuram a atual exposição da bacia (Costa Neto 1997; Testa \& Bosence 1998, 1999; Gomes et al. 2008a, 2008b; Vital et al. 2008). Sua estratigrafia rasa na região costeira apresenta rochas sedimentares do Neógeno, composta por três unidades litoestratigráficas denominadas Formação Tibau (arenitos e conglomerados), Formação Guamaré (calcários) e Formação Ubarana (folhelhos marinhos). Estas unidades compõem um grande ciclo

1 - Programa de Pós-Graduação em Geodinâmica e Geofísica, PRH-ANP22, Universidade Federal do Rio Grande do Norte, Natal (RN), Brasil. E-mail: moabpx@yahoo.com.br

2 - Pós-Graduação em Geodinâmica e Geofísica, Departamento do Geologia, PRH-ANP22, Universidade Federal do Rio Grande do Norte, Natal (RN), Brasil; pesquisador CNPq. E-mail: helenice@geologia.ufrn.br 


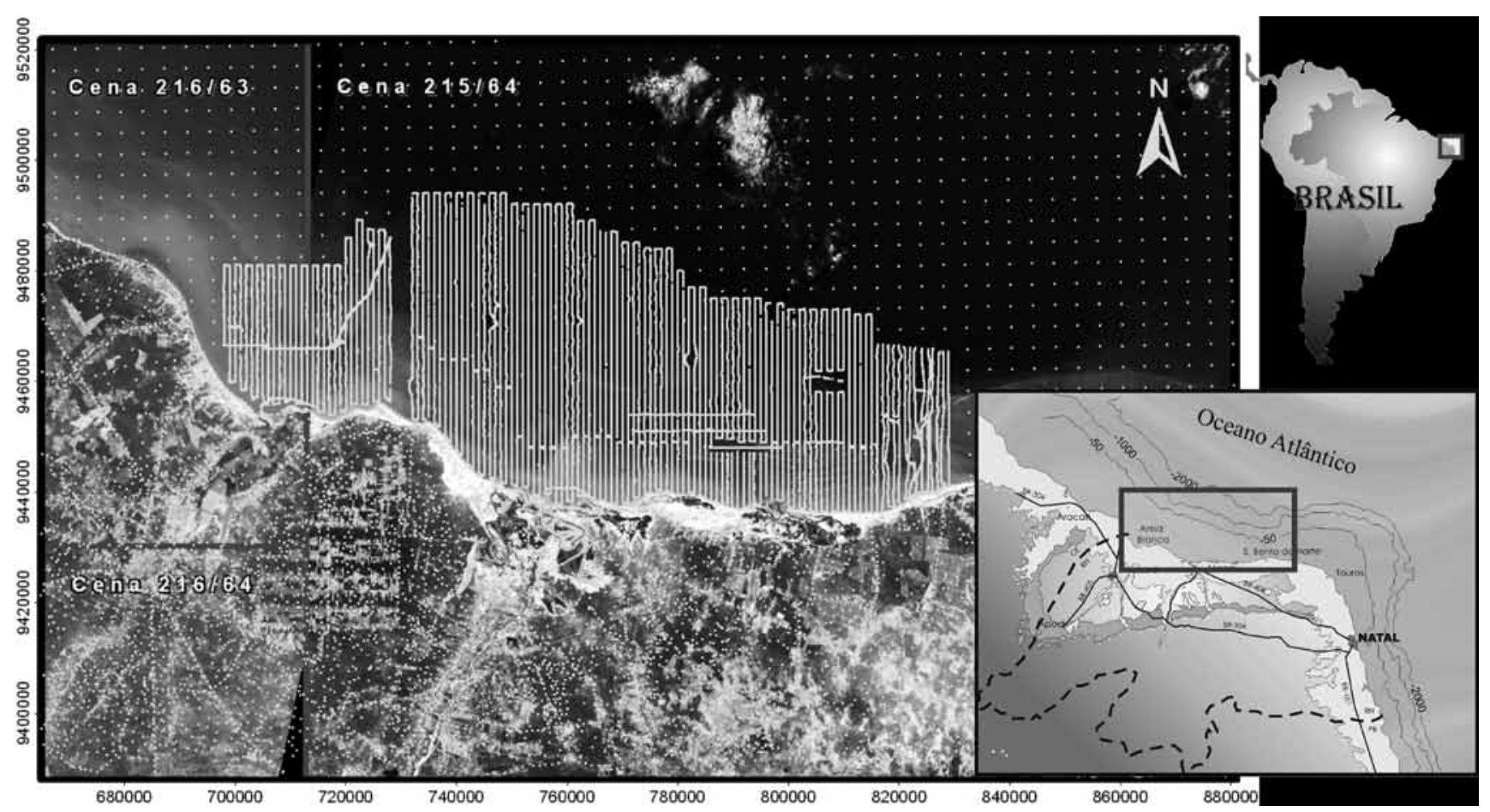

Figura 1 - Mosaico das cenas 216/63, 216/64 e 215/64 (215/64 com deslocamento para norte do imageamento) do sensor ETM+/LandSat-7 e distribuição espacial das estações altimétricas e batimétricas, localizadas na plataforma continental norte do Rio Grande do Norte. Composição colorida RGB 321 com equalização dos histogramas (ERMapper 6.4) englobando as extensões da Bacia Potiguar em ambientes terrestres, plataformais e mar profundo.

regressivo iniciado no Neocampaniano, estendendo-se até o Holoceno, formando um sistema costeiro-plataforma-talude-bacia (Pessoa Neto 2003).

Essa região é favorecida, na visualização de produtos de sensores, por possuir águas claras sazonalmente (baixa turbidez observada nas imagens) sobre a plataforma. Entretanto, visando a otimização dessas imagens e a obtenção de informações mais relevantes sobre a superfície de fundo, utilizou-se a proposta de Gomes (2007b) do método de processamento digital de imagens aplicado ao realce de imagens em ambiente marinho e a visualização tridimensional com análise geoestatística dos dados batimétricos (Gomes et al. 2007c). O resultado é expresso pela compartimentação geomorfológica da plataforma continental norte do Rio Grande do Norte.

MÉTODOS Os dados batimétricos foram levantados pelo GGEMMA (Vital \& Frazão 2005), abrangendo áreas da plataforma continental interna até o talude, e processados por Gomes et al. (2007a, 2007c). Neste trabalho, os dados foram selecionados para a área de interesse (Fig. 1) e re-processados pelas análises geoestatísticas. Tais dados serviram para caracterização do relevo marinho na plataforma continental da Bacia Potiguar através da modelagem tridimensional.

A imagem utilizada foi adquirida pelo sensor LandSat7 ETM+ (Enhanced Thematic Mapper Plus), correspondente a órbita 215/64 deslocada a $130 \mathrm{Km}$ para norte do imageamento datada de 11/06/2002, e as cenas 216/63 e 216/64 imageadas em 13/08/1999, compondo um mosaico com todas as bandas do visível e infravermelho (Fig. 1). Esta imagem foi convenientemente delimitada na área de interesse e tratadas no ambiente do ERMapper 6.4 por Gomes (2007b), permitindo a integração com os demais dados e sua utilização em diversas etapas deste trabalho.

A aplicação das técnicas de Processamento Digital de Imagens - PDI proposta por Gomes (2007b) deu-se no intuito de amplificar/equilibrar a intensidade das respostas da radiação, atenuada pelos processos seletivos de absorção, e indicar uma metodologia apropriada para o realce das imagens em ambientes individualizados por padrões específicos de contraste, como: o terrestre, o marinho raso e profundo. Baseando-se em princípios físicos e estatísticos de distribuição espectral para os diferentes ambientes imageados foram utilizadas as técnicas de PDI disponíveis no ERMapper 6.4 e ENVI. O processamento digital foi individualizado nos ambientes terra e mar por meio de "máscaras-polígonos", que permitiram diminuir a dispersão da variável estudada (reflectância) e assim aumentar a concentração proporcional dos valores na equalização dos histogramas. Considerando que essa correlação entre a variável nos ambientes marinho e terrestre na região é independente, procurou-se fazer um realce de contraste separadamente para os pixels de cada região. A validação dos resultados das composições e equalizações de histogramas tomou por base 
o nível de resolução e clareamento sobre a plataforma continental interna e externa, talude e sopé, e a preservação da qualidade das imagens em regiões próximas à linha de costa, superando as dificuldades de equalização local e global, facilitando a aplicação de filtros e ganhos. O resultado final (Fig. 2) foi o balanço compensado dos histogramas nos ambientes individualizados, aumentando a precisão visual para a parte imersa rasa e profunda da Bacia Potiguar, melhorando a definição de classes. O PDI aplicado permitiu o mesmo resultado ao mosaico de imagens da região.

RESULTADOS E DISCUSSÕES A visualização e interpretação das principais feições da Plataforma Continental Norte do Rio Grande do Norte baseou-se na caracterização geomorfológica obtida na literatura (Vital et al.

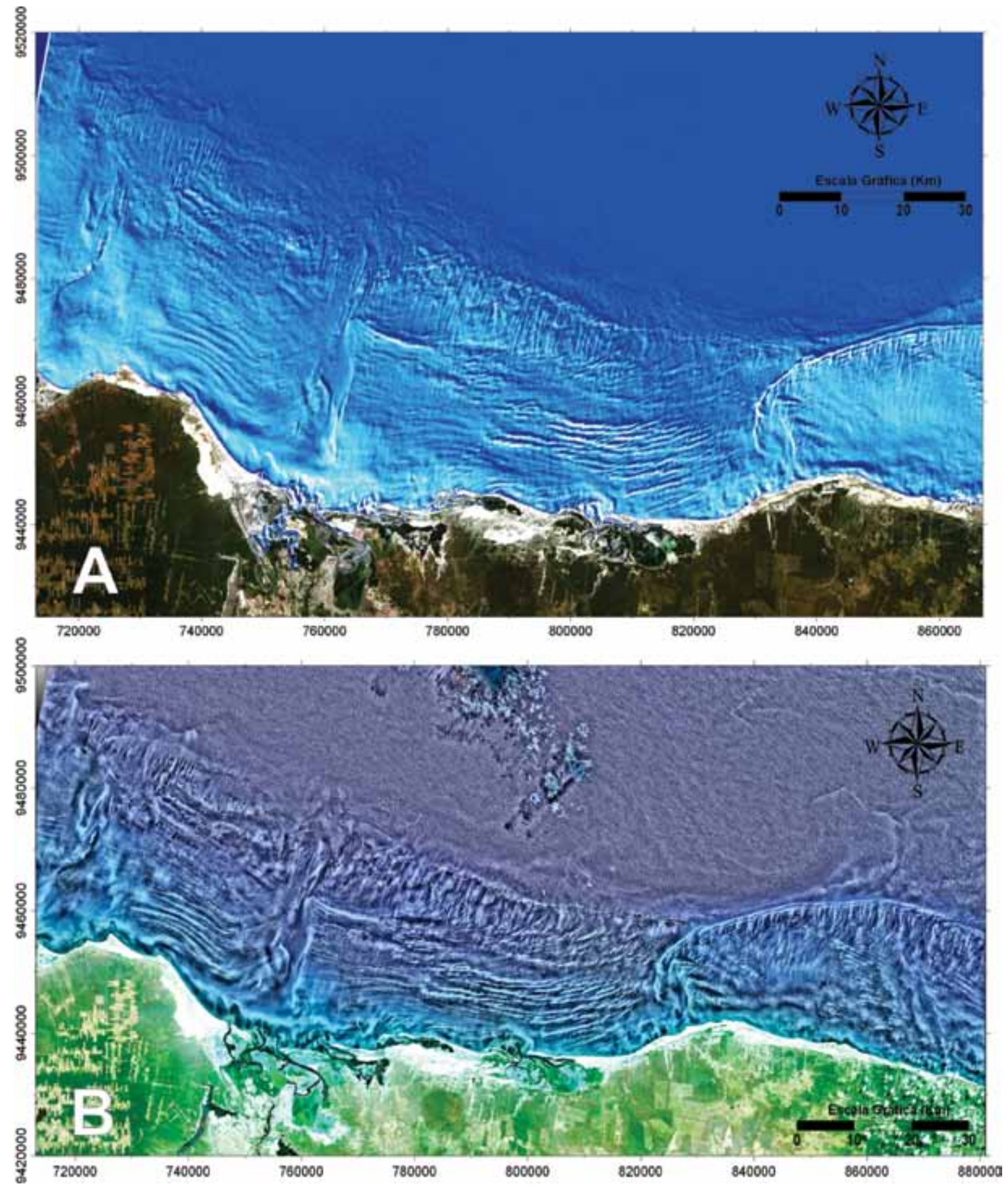

Figura 2 - Imagens LandSat 7 ETM+ da área como exemplo do processamento digital individualizado para os ambientes de continente (RGB321) e de plataforma (RGB321 com filtro direcional). A) Realce de contraste com filtro direcional (Gomes et al. 2007b). B) Filtro direcional aplicado com compensação de intensidade ao longo do histograma de níveis de cinza. 
2005, 2008; Lima \& Vital 2006; Tabosa 2006; Tabosa \& Vital 2006; Tabosa et al. 2007), e foram complementadas com a análise dos dados batimétricos, das imagens orbitais e da construção de Modelos Digitais de Terreno (MDT).

A utilização de imagens LandSat integradas ao MDT dos dados batimétricos permitiu identificar as feições sobre a plataforma e foi possível compartimentar a plataforma continental na área entre São Bento do Norte e Areia Branca em plataforma interna, plataforma média e plataforma externa. Embora trabalhos anteriores (Kempf 1970; Coutinho 1976) propuseram uma subdivisão de caráter regional para a plataforma continental, ainda não havia sido realizada uma integração dos dados atualmente existentes para a região a contento. Kempf (1970) propôs uma primeira divisão da plataforma continental brasileira com o limite marcado pela mudança da flora algária. Em seguida, Coutinho propôs outra subdivisão para a plataforma continental nordestina, considerando características sedimentológicas e morfológicas. No presente trabalho propõe-se a subdivisão para a plataforma na região norte do estado do Rio Grande do Norte partindo das informações extraídas dos dados batimétricos e da análise de imagens de satélite tratadas neste trabalho. Com esses dados foi feita a caracterização morfométrica e o reconhecimento das feições e, correlacionando os novos dados processados aos dados sedimentológicos preexistentes (Vital et al. 2008), foram delimitados os ambientes da plataforma continental.

$\mathrm{O}$ ambiente marinho estudado apresenta fisiografia de plataforma continental e talude, com um máximo de $43 \mathrm{~km}$ de largura entre Areia Branca e São Bento do Norte, limitada pela linha de costa e estendendo-se em direção ao talude, com transição em profundi- dades entre de 40 e $60 \mathrm{~m}$ (Fig. 3). A plataforma pode ser dividida em plataforma interna, média e externa com base na caracterização geomorfológica e sedimentológica. A plataforma interna é limitada pela isóbata de 15 $\mathrm{m}$ com relevo suave envolvendo extensos campos de dunas longitudinais, com predominância de sedimentos siliciclásticos; a plataforma média está limitada entre as isóbatas de $15 \mathrm{~m}$ e $25 \mathrm{~m}$, caracterizada pela ocorrência mista de sedimentos e dunas transversais; a plataforma externa é estreita com declividade superior à da plataforma média e limita-se entre as isóbatas de 25 até 40 $\mathrm{m}$ de profundidade. $\mathrm{O}$ limite entre a plataforma média e externa é bem marcado, na porção central desta plataforma, por uma extensa linha de antigas rochas praiais. Essa região de plataforma externa apresenta predominância de sedimentos bioclásticos e proeminentes desníveis batimétricos. Do limite externo da plataforma ao início da planície abissal, ocorre um desnível superior a $2000 \mathrm{~m}$ sobre o talude e o sopé continental.

As principais feições submarinas observadas sobre a plataforma continental são: região de dunas subaquáticas (na porção oeste da área, campos de dunas de Galinhos e dunas longitudinais frente a Diogo Lopes); campo de dunas longitudinais na plataforma interna; os vales incisos do Rio Açu e do Rio Apodi-Mossoró (os rios mais importantes da região); dunas transversais na plataforma média; rochas praias (beachrocks); e corpo arenoso marinho raso isolado (Coroa das Lavadeiras na porção leste da área) (Fig. 4).

Rochas Praiais (beachrocks) A identificação das rochas praiais (beachrocks) na plataforma é de grande importância na correlação entre a variação do nível do

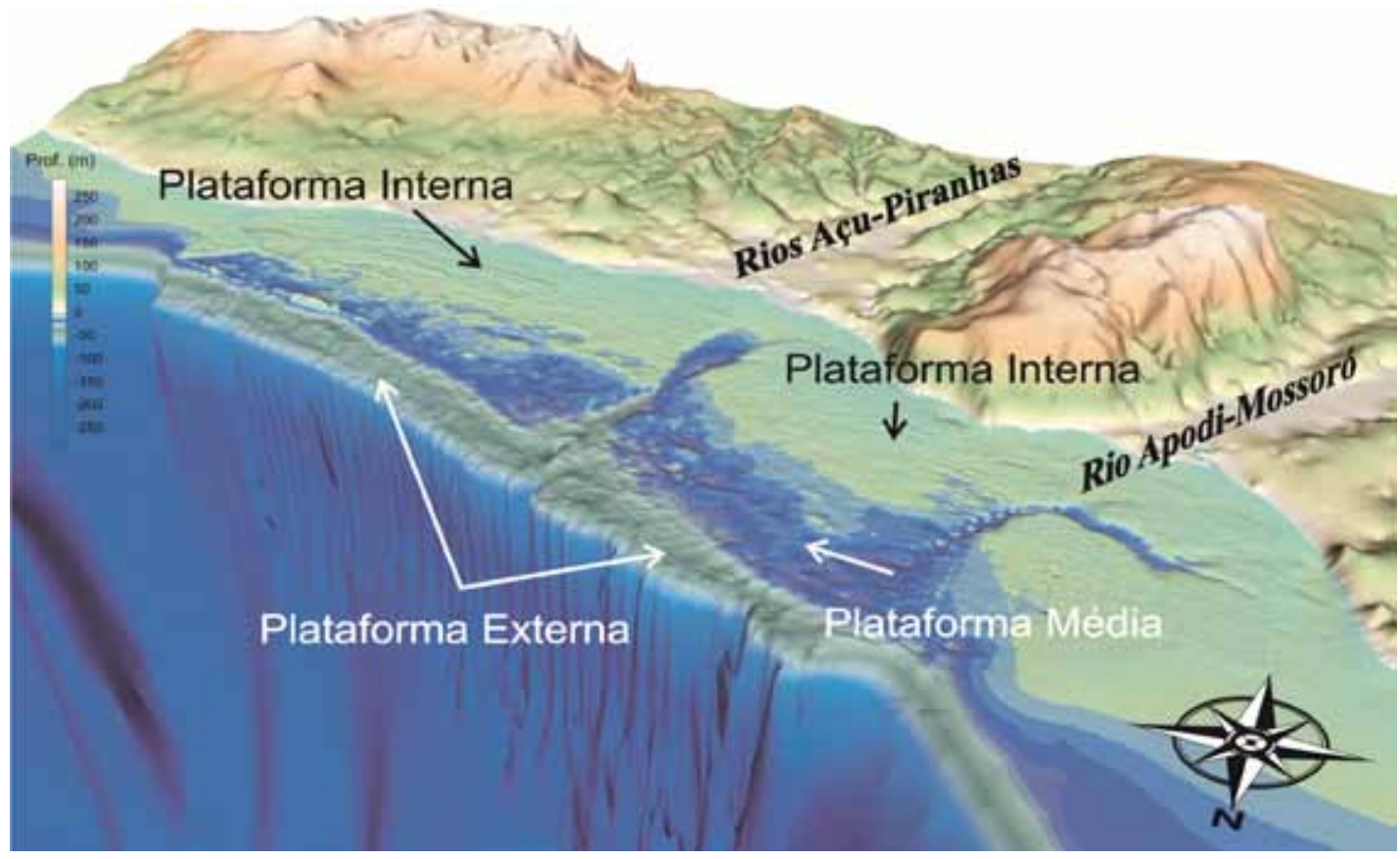

Figura 3 - Modelo Digital do Terreno destacando a delimitação da plataforma continental em interna, média e externa. 


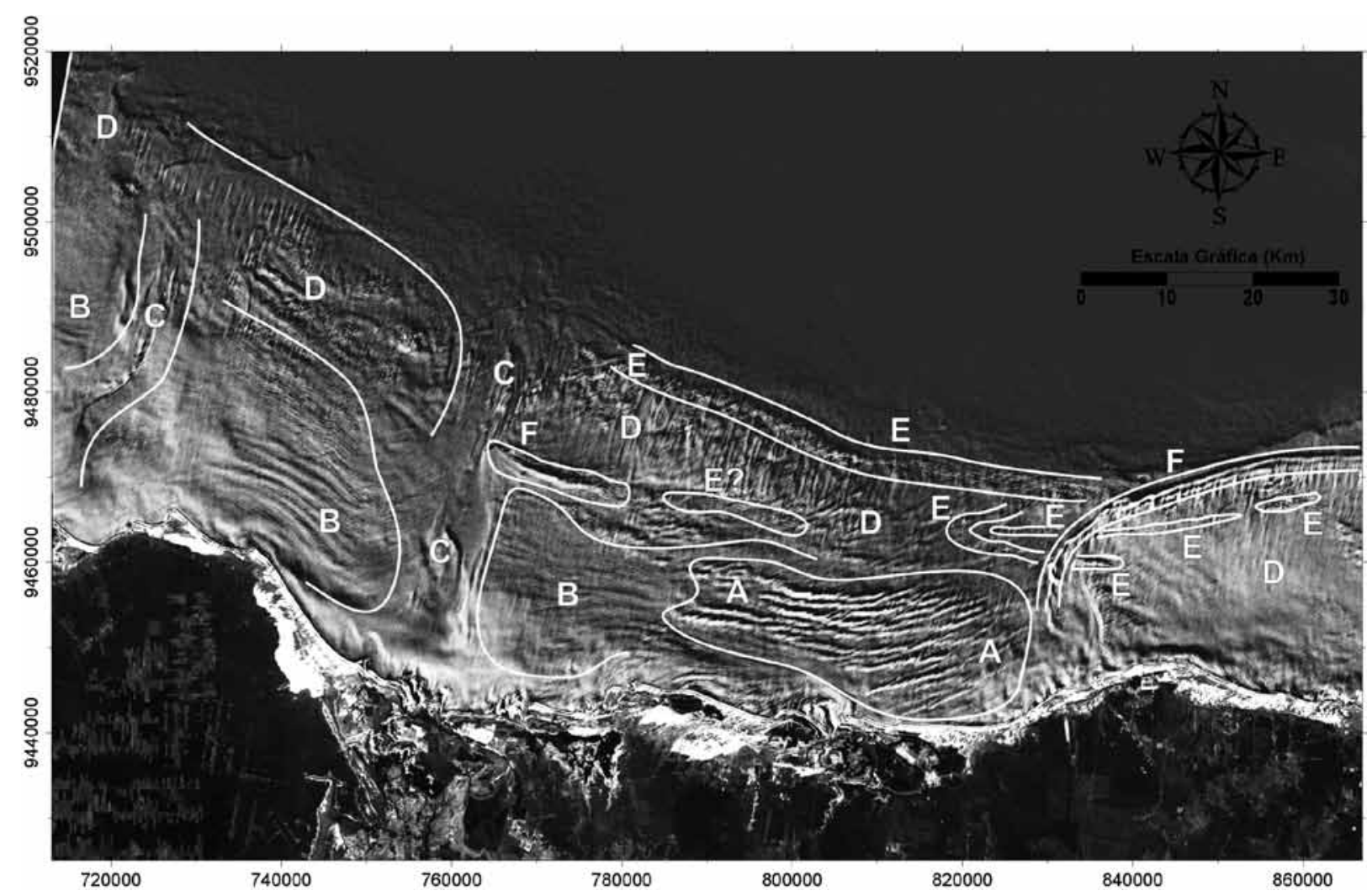

Figura 4 - Imagem LandSat7 processada por Gomes (2007b), destacando as principais feições geomorfológicas (modificado de Vital et al. 2008) sobre a Plataforma Continental norte do RN. A) Campos de Dunas longitudinais simétricas e assimétricas; B) Dunas subaquáticas longitudinais paralelas à costa; C) Paleocanais do Rio Açu (leste) e Rio Mossoró (oeste); D) Campos de Dunas transversais; E) Linhas de rochas praiais (beachrocks); F) Corpos arenosos marinho raso isolados.

mar e a incisão do paleovale, pois representam antigas linhas de costa (originadas nas zonas de intermaré). A cimentação das rochas praiais é gerada por carbonato de cálcio e ocorre num processo rápido em períodos de 10 a 15 anos, preservando a evidência da posição do nível relativo do mar para a sua formação.

As linhas de rochas praiais (Figs. 4-E e 5) identificadas estão geralmente dispostas na direção E-W. Alguns destes afloramentos submarinos são interceptados e cobertos pela formação de corpos arenosos isolados na região ao longo da Coroa das Lavadeiras (Fig. 4-F e 5) e seguem em direção ao Alto de Touros. Alguns corpos com mesma resposta espectral são identificados em frente a Diogo Lopes distando cerca de $17 \mathrm{~km}$ da linha de costa atual. Devido à inclinação (basculamento) e à cobertura por sedimentos dos blocos das rochas praiais, estes se apresentam na imagem de satélite mais estreitos do que em sua largura real, o que pode ser comprovado com fotografias subaquáticas e registro batimétrico. O lineamento mais extenso localiza-se próximo à quebra da plataforma, com expressão contínua entre a Coroa das Lavadeiras, em frente à região de São Bento do Norte, e o vale inciso do Rio Açu. Este lineamento apresenta um desnível batimétrico na porção leste, próximo à Coroa das Lavadeiras (Minhoto), podendo ser de origem neotectônica, chegando a aflorar acima do nível relativo do mar atual (Fig. 5-B).

Corpo Arenoso Marinho Raso Isolado e Dunas No trecho da plataforma localizado próximo à São Bento do Norte e à Ponta dos Três Irmãos é observado na morfologia de fundo uma feição conhecida localmente como "Coroa das Lavadeiras" (Fig. 4-F e 6). Esta feição pode ser geomorfologicamente caracterizada como um corpo arenoso marinho raso isolado (Tabosa 2006; Tabosa \& Vital 2006; Vital et al. 2008). Apresenta-se como um alto em forma curva posicionado paralelamente à linha da costa com mudança de direção do seu contorno para sudoeste, por vezes se sobrepondo a linhas de rochas praiais.

As estruturas sedimentares observáveis nas imagens de satélite são interpretadas como o retrabalhamento dos sedimentos por correntes, provocando deposição ou erosão, deixando a água turva. As diversas formas de feições submarinas são modeladas pela ação de correntes indicando que os tipos de feições e suas formas (transversais e longitudinais) dependem da velocidade do fluxo e do tipo de sedimento recobrindo a plataforma. No entanto, a Coroa das Lavadeiras, formada na extremidade oeste do Alto de Touros, constitui uma barreira para o transporte sedimentar (Tabosa \& Vital 2006). Esse obstáculo, juntamente com a incipiente contribuição de sedimentos pelos rios, proporciona 

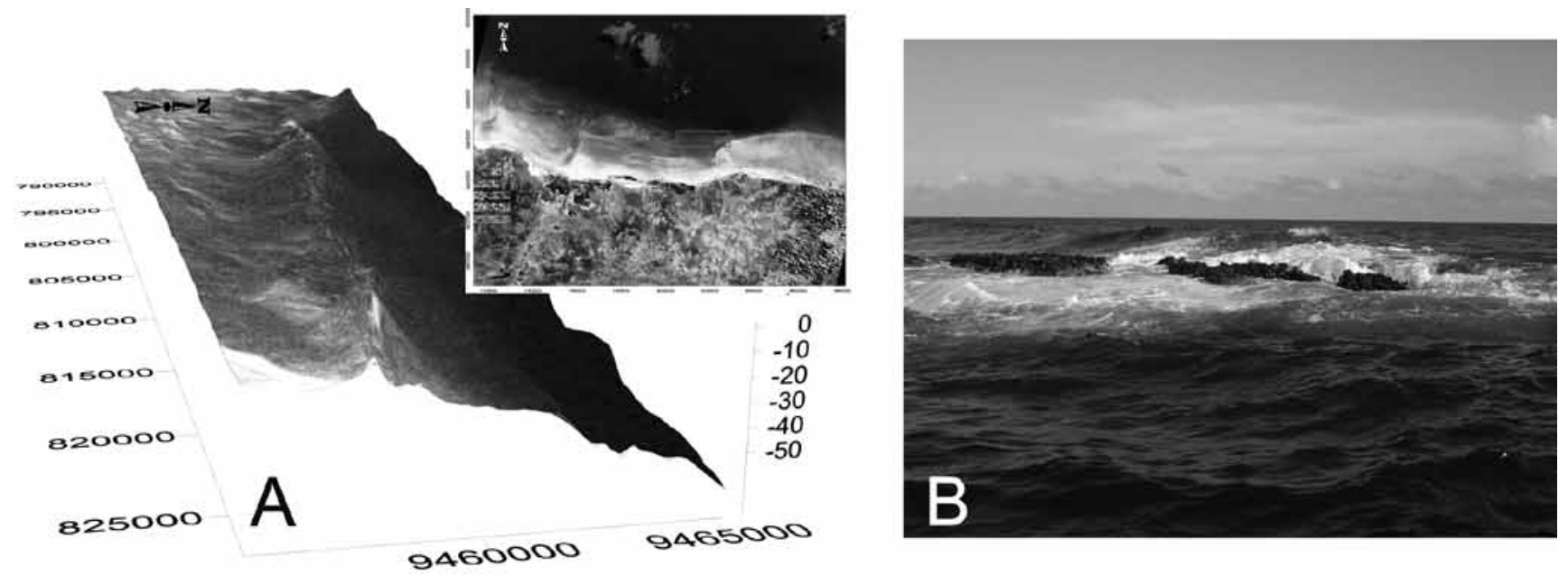

Figura 5 - A) MDT/Imagem da linha das rochas praiais localizadas próximo à quebra da plataforma. B) Rochas praiais acima do atual nivel do mar (Foto: I. Cabral Neto). Modificado de Gomes (2007a).
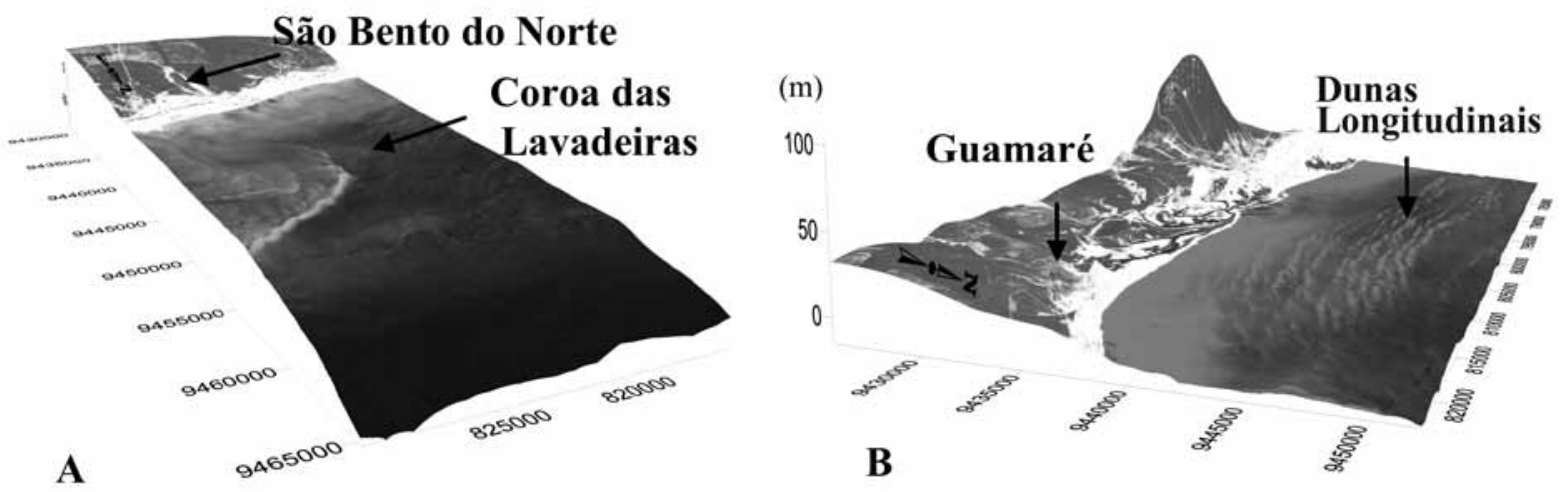

Figura 6 - A) Corpo arenoso submerso isolado - Coroa das Lavadeiras; B) Campo de dunas longitudinais frente a Galinhos (Modificado de Gomes 2007a).

a pequena quantidade de sedimentos em suspensão na plataforma. A não-deposição desses sedimentos e a atenuação da força das correntes oriundas do atlântico contribuem para uma melhor preservação das paleofeições e uma melhor visualização por imagens orbitais.

É observado um campo de dunas subaquáticas que se desenvolvem a oeste da Coroa das Lavadeiras, porém com menor amplitude batimétrica (Fig. 4-A e 6). Essas dunas apresentam-se orientadas longitudinalmente na direção NE-SW, sendo formas de leito simétricas e assimétricas de grande comprimento de onda, que indicariam sentido das correntes sobre a plataforma para NW (Vital et al. 2008). Quando observadas em menor escala tem-se o alinhamento aproximado do conjunto de dunas na direção EW que se estende por toda área identificada na figura 4-A. Segundo dados de três estações oceanográficas (sensores tipo S4) instaladas sobre a plataforma, somente a estação próxima à Coroa das Lavadeiras apresentou, no ano de 2004, correntes predominantes na direção NE, as outras duas estações locadas frente à Guamaré indicaram direções predominantes no sentido W e NW (Vital et al. 2008). As dunas simétricas apresentam comprimento variando de $100-500 \mathrm{~m}$ e altura entre 0,5 a $6 \mathrm{~m}$, as assimétricas apresentam comprimento variando de 60-190 e altura entre $0,5-1 \mathrm{~m}$, e distância máxima entre cristas é de 1,5 Km (Gomes et al. 2007a).

Lateralmente a esse campo de dunas e a margem leste e oeste do paleovale do Rio Açu, na extensão da plataforma interna, ocorrem dunas longitudinais (Fig. 4-B), que apresentam uma extensão contínua e paralela à linha de costa, estendendo-se desde a profundidade de $2 \mathrm{~m}$ até o início da plataforma média. A morfologia de cristas e cavas apresenta larguras variando 300 e $800 \mathrm{~m}$, alturas entre 1 e $3 \mathrm{~m}$ e comprimento entre 300 e $1500 \mathrm{~m}$.

$\mathrm{Na}$ plataforma média observa-se um padrão de dunas transversais perpendiculares à linha de costa 
(Fig. 4-D), diferindo dos demais padrões já citados. Essas dunas também podem ser observadas nas imagens de satélite sobre a plataforma adjacente, a Plataforma de Aracati (Oliveira et al. 2008), e sobre o Alto de Touros (Viana et al. 1991; Testa e Bosence 1998). Sua origem ainda é pouco discutida, mas pode estar ligada a correntes mais profundas que atingem a borda da plataforma.

Sistema de Vales Incisos Sobre esta porção da plataforma são identificados dois expressivos vales incisos, que recebem o nome dos dois principais rios da estrutura hidrográfica da planície costeira meio-norte do Rio Grande do Norte: Rio Piranhas-Açu e Rio Apodi-Mossoró. Estão situados perpendicularmente à costa em áreas de baixo gradiente em direção ao mar, onde formam superfícies de inundação planas a suavemente inclinadas (planície de maré e flúvio/estuarina).

O Rio Apodi-Mossoró é o segundo rio de maior importância do estado, devido à sua extensão. Com nascente localizada na serra de Luís Gomes (RN), passa pelos municípios localizados na chapada do Apodi e pela cidade de Mossoró, despeja suas águas no Oceano Atlântico, entre os municípios de Grossos e Areia Branca.

O paleovale do rio Apodi-Mossoró sobre a plataforma (Fig. 4-C e 7) esteve ligado, em situação de nível de mar baixo, a pelo menos três rios. Provavelmente $o$ arrasamento das isóbatas das extremidades desses canais foi causado por aumento de espaço de acomodação e, conseqüentemente, deposição de sedimentos fluviais. Lima (2006) e Lima \& Vital (2006) descrevem as características morfológicas do paleocanal, as quais indicam duas direções para o canal (NW-SE e NE-SE) e profundidades máximas de $30 \mathrm{~m}$. Segundo os dados de batimetria e altimetria integrados no MDT (Fig. 7), pode-se reconhecer direções das principais feições estruturais que interligam o paleocanal aos rios correspondentes no continente.

O Rio Piranhas-Açu nasce na Serra do Bongá (PB) com o nome de Piranhas recebendo águas dos rios Piancó e Peixe. Entra no estado do RN pelo município de Jardim de Piranhas e recebe o nome Piranhas-Açu, passando a receber as águas de todos os rios que formam a bacia da região do Seridó e sendo represado pela Barragem Engenheiro Armando Ribeiro Gonçalves. O rio continua o seu curso exorréico, indo desaguar no Oceano Atlântico, nas imediações da cidade de Macau.

A depressão deste grande rio moderno, o Rio Açu, estende-se desde a foz até a borda da plataforma, onde é identificado um paleocanal imerso (Fig. 8), atingindo profundidades máximas de $32 \mathrm{~m}$ na plataforma, se estende como vale inciso até o talude, nesse ponto distando $35 \mathrm{~km}$ da foz e com mesma orientação NNE do atual.

Esses dois grandes rios são interpretados como vales incisos formados em situação de queda do nível do mar, e posteriormente preenchidos por sedimentos pleistocênicos e holocênicos (Schwarzer et al. 2006; Lima 2006; Lima \& Vital 2006; Vital et al. 2008, Gomes et al. 2008a), que na superfície do interior do vale do Açu são compostos por lama terrígena (proximal) e mudam para lama carbonática nas porções mais distais da plataforma (Vital et al. 2005, 2008).

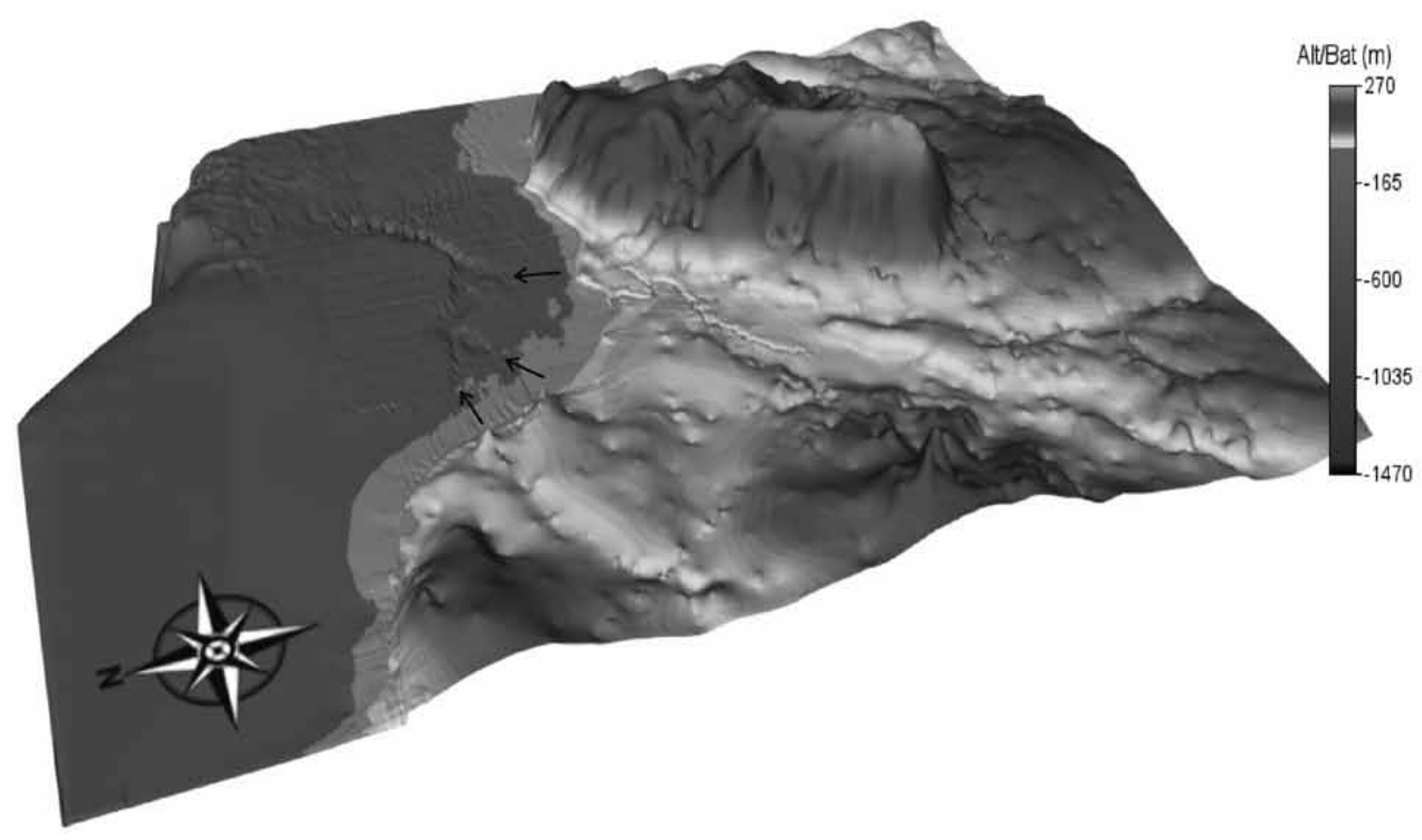

Figura 7 - MDT da região do Rio Apodi e do seu paleovale sobre a plataforma, indicando os possiveis sentidos dos rios que alimentavam o antigo vale. 

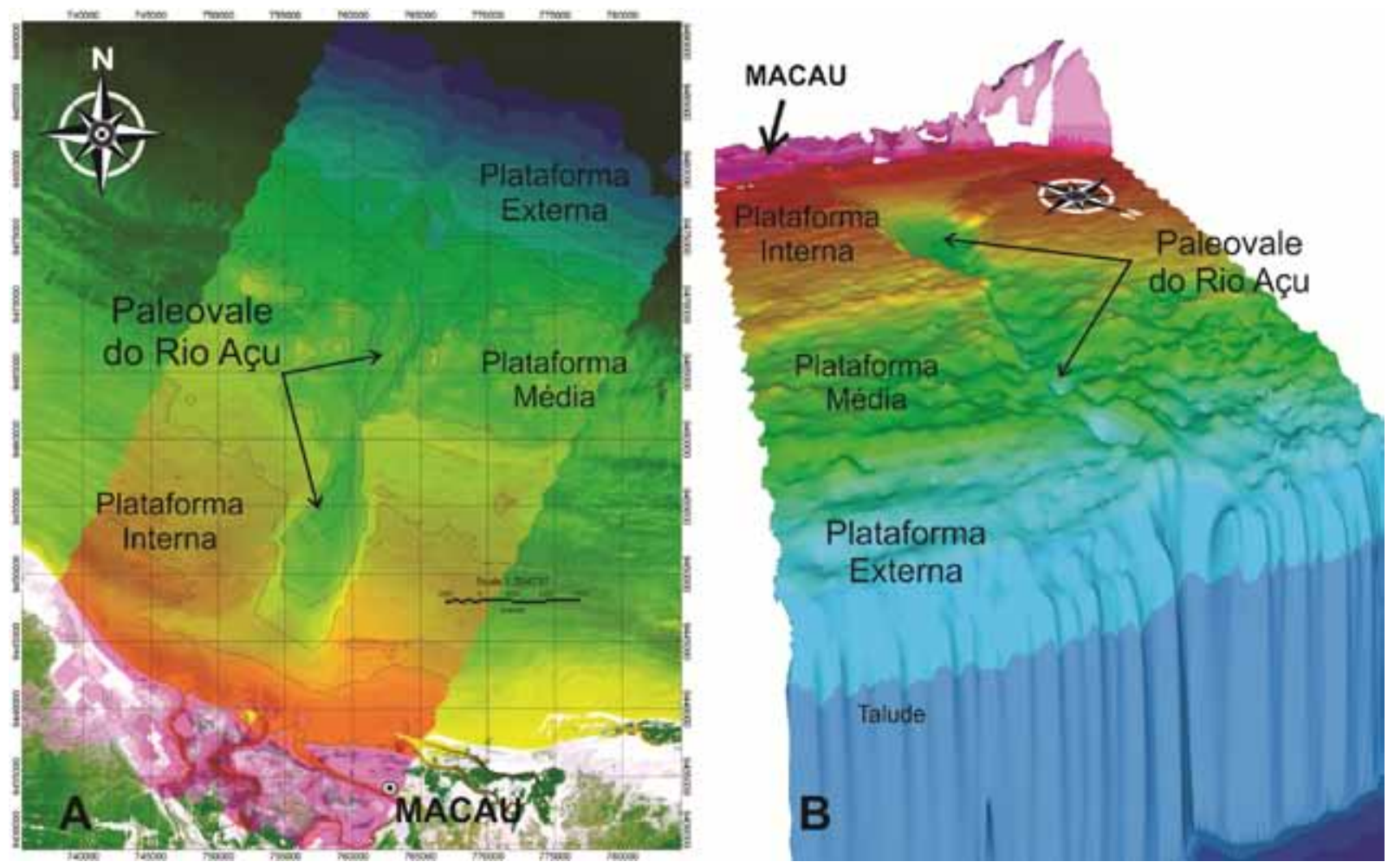

Figura 8 - (A) Imagem com batimetria em curvas de nivel e (B) MDT da região do paleovale do Rio Açu sobre a plataforma interna (tons vermelho-amarelados), média (tons verdes) e externa (tons azuis).

CONSIDERAÇÕES FINAIS Este trabalho apresentou resultados da investigação geomorfológica em ambiente de plataforma continental rasa, por meio do processamento digital de imagens LandSat e do tratamento geoestatístico dos dados batimétricos para criação de Modelos Digitais de Terreno. Os dados foram processados e integrados empregando a metodologia proposta por Gomes $(2007 \mathrm{~b}, 2007 \mathrm{c})$ que permitiu maior realce das feições geomorfológicas em ambiente marinho raso. Foi realizada a caracterização e compartimentação de diversas feições sobre a plataforma, como campos de dunas, vales incisos, rochas de praia e corpos arenosos isolados, concluindo com a subdivisão da plataforma continental em interna, média e externa na área entre São Bento do Norte e Areia Branca.

Agradecimentos Agradecimentos são devidos a ANP-PRH22 pela bolsa de doutorado. Esta pesquisa foi realizada com suporte financeiro dos projetos SISPLAT e POTMAR (REDE 05 FINEP-CTPETROPETROBRAS) e auxilio a pesquisa $\mathrm{CNPq}$ numero 312275_2006-4.

\section{Referências}

Costa Neto L.X. 1997. Evolução geológica-geomorfológica recente da plataforma continental interna ao largo do delta do Rio Açu, Macau - RN. Dissertação de Mestrado, Programa Geologia e Geofísica Marinha da Universidade Federal Fluminense, Rio de Janeiro, 214 p.

Coutinho P.N. 1976. Geologia marinha da plataforma continental Alagoas-Sergipe. Tese de Livre Docência, Universidade Federal de Pernambuco, 119 p.

Gomes M.P., Vital H., Macedo J.W.P. 2007a. Modelo digital do terreno-MDT de áreas sob atuação da indústria petrolífera através da integração de dados batimétricos e altimétricos da zona costeira norte do RN. In: Congresso Brasileiro de P\&D em Petróleo e Gás, 4, Atas, CD-Rom. Disponível em: http://www.portalabpg.org.br/PDPetro/4/resumos/4PDPETRO_1_2_0096-1.pdf. Acessado em 21 mai 2009.

Gomes M.P., Vital H., Macedo J.W.P. 2007b. Processamento Digital de Imagens Multiespectrais Aplicado no Realce dos Ambientes Marinho Raso e Profundo da Região de Plataforma Continental e Talude da Bacia Potiguar. In: Simpósio de Geologia do Nordeste, 22, Atas, p. 162.

Gomes M.P., Vital, H., Macedo J.W.P. 2007c. Aplicação da geoestatística na filtragem de dados batimétricos e altimétricos na bacia potiguar. Revista de Geologia, 20(2):243-255.

Gomes M.P., Vital H., Macedo J.W.P., Frazão E.P. 2008a. Incised valley system: Insights from high-resolution seismic stratigraphy and geomorphologic modeling from the Açu River mouth and shelf, Potiguar Basin, NE Brazil. In: AAPG Annual Convention and Exhibition in San An- 
tonio - Texas, USA, Abstract Volume, p. 69. Selected to: 2008 AAPG Student Poster Awards Competition, Shell and AAPG Student Chapters Committee.

Gomes M.P., Vital H., Macedo J.W.P. 2008b. Underwater acquisition and processing of high resolution data seismic in modern continental shelf of Potiguar Basin, atlantic margin of northeast Brazil. In: International Geological Correlation Program Project No. 526 Risks, Resources, and Record of the Past on the Continental Shelf: Mining Late Quaternary Geological Evidence - $2^{\text {nd }}$ Annual Conference (South America), Natal-RN, Brazil, Abstract Volume, p. 45.

Kempf M. 1970. Notes on the benthic bionomy of N.E. Brazilian shelfs. Mar. Biol. 5(3):213-214.

Lima S.F. 2006. Caracterização geomorfológica e paleogeográfica da plataforma continental adjacente à foz do rio Apodi-Mossoró, RN. Dissertação de Mestrado, Programa de Geodinâmica e Geofísica, Universidade Federal do Rio Grande do Norte, 109 p.

Lima S.F., Vital H. 2006. Geomorphological and paleogeographic characterization of continental shelf of the Apodi-Mossoró River, RN-Brazil. In: Brebbia C.A. (eds.) Environmental Problems in Coastal Regions VI: Including Oil Spill Studies. Wessex Institut of Technology, Cambridge Printing, p. 351-360.

Oliveira P.R.A., Vital H., Sá Freire S.G., Gomes M.P. 2008. Padrões sonográficos de fundo da Plataforma Continental Brasileira adjacente aos municípios de Icapuí e Aracati CE. In: Simpósio Brasileiro de Geofísica, 3, CD-Rom.

Pessoa Neto O.C. 2003. Estratigrafia de seqüências da plataforma mista neogênica na Bacia Potiguar, margem equatorial brasileira. Revista Brasileira de Geociências, 33:263-278.

Schwarzer K., Stattegger K., Vital H., Becker M. 2006. Holocene coastal evolution of the Rio Açu area (Rio Grande do Norte, Brazil). Journal of Coastal Research, 39:141145.

Tabosa W.F., Amaro V.E., Vital H. 2007. Caracterização do ambiente costeiro, integrado a produtos de sensoriamento remoto na região de São Bento do Norte/Caiçara do Norte - NE Brasil. Revista Brasileira de Geofísica, 25(1):37-48.

Tabosa W.F. 2006. Morfologia e sedimentologia da plataforma continental brasileira adjacente a São Bento do Nor- te e Caiçara do Norte. Tese de Doutoramento, Programa de Geodinâmica e Geofísica, Universidade Federal do Rio Grande do Norte, 167 p.

Tabosa W.F. \& Vital H. 2006. Hydrodynamic forcings and environmental impacts on the coast and shelf adjacent to Sao Bento do Norte, NE Brazil. In: Brebbia C.A. (eds.) Environmental Problems in Coastal Regions VI: Including Oil Spill Studies. Wessex Institut of Technology, Cambridge Printing, p. 165-174.

Testa V., Bosence D.W.J. 1998. Carbonate-siliciclastic sedimentation on high-energy, ocean-facing, tropical ramp, NE Brazil. In: Wright V.P. \& Burchette T.P. (eds.) Carbonate Ramps, Geol. Soc. London, 149 Spec. Pub., p. $55-71$.

Testa V., Bosence D.W.J. 1999. Physical and biological controls on the formation of carbonate and siliciclastic bedforms on the north-east Brazilian Shelf. Sedimentology, 46:279-301.

Viana M.L., Solewicz R., Cabral A.P., Testa V. 1991. Sandstream on the northeast Brazilian Shelf. Continental Shelf Research, 2:509-524.

Vital H. \& Frazão E.P. 2005. Carta batimétrica da plataforma continental brasileira adjacente ao setor norte do estado do Rio Grande do Norte: Galinhos a Ponta do Mel. Workshop Rede PETROMAR, Natal-RN, Atas, CDRoom.

Vital H., Silveira M., Amaro V.E. 2005. Carta sedimentólogica da plataforma continental brasileira - área Guamaré a Macau (NE Brasil), utilizando integração de dados geológicos e sensoriamento remoto. Revista Brasileira de Geofísica, 23(3):233-241.

Vital H., Stattegger K., Amaro V.E., Schwarzer K., Frazão E.P., Tabosa W.F., Silveira I.M. 2008. A modern highenergy siliciclastic-carbonate platform: Continental shelf adjacent to northern Rio Grande do Norte State, northeastern Brazil. In: Hampson G.J., Steel R.J., Burgess P.M., Dalrymple R.W. (eds.) Recent advances in models of siliciclastic shallow-marine stratigraphy. SEPM, 90, Spec. Pub., p.175-188.

Manuscrito ID 14860

Submissão 23 de julho de 2009 Aceito em 01 de setembro de 2010 